\title{
CORRELATION BETWEEN DIFFERENT FORMS OF SENSORY DISCRIMINATION
}

\author{
By John A Stevenson, University of Illinois
}

\section{TABLE OF CONTENTS}

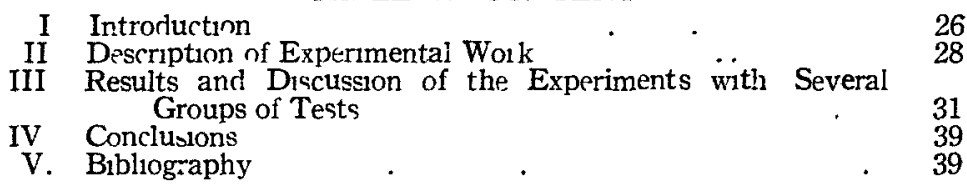

\section{Introduction}

The study of relationships between mental traits and between mental traits and physical traits has centered mainly about four problems:

1. How are the various mental and physical traits interrelated? Such problems as the correlations between sensory discrimination and memory, between memory and reasoning ability, between motor functions and mental functions, etc., have been studied. The investigations have so far yielded discordant results, and the question of the relative dependence or independence of various traits and functions has given rise to much controversy.

2 How are the various mental and physical traits related to general mental ability or general intelligence? The interest in this problem has been due, no doubt, to the possibility of discovering some one trait or group of traits, the measurements of which might serve as an index of mental makeup. The difficulty of securing an unambiguous measure of general intelligence, as well as a satisfactory measure of special mental traits, has led again to w1dely varying results.

3 How are the results of mental functions, as shown in school subjects, correlated? The practical bearings of such determinations on the grouping of subjects and their disciplinary value, as well as the light they might throw on the relationship between various mental processes, have led to numerous investigations on correlations between school marks

4. How are the abilities with varying data in what is in descriptive psychology ordinarily called a single mental func- 
tion, correlated? Such problems as the correlation between memory for colors, sounds, numbers, words, etc., between immediate memory and secondary memory, between memories as affected by various modes of presentation, have recerved some attention.

The accumulating evidence on these four problems has shown a surprising lack of correlation in cases where common observation and opinion would have led one to expect a high correlation (9) ${ }^{1}$ The evidence points apparently to a great specialization in mental functions and marked independent variability. So marked is this independence and so contradictory oftentimes to common experience that one is led to suspect that the lack of correlation is due to the presence or absence of factors other than those supposedly measured. Moreover, the more recent investigations have shown that the earlier extreme view of specialization and independence is not tenable Thus Thorndike (9) is inclined to distingursh at least three levels of mental action-sensitivity, association, and analysis, which would show "closer intro than inter-relations" It is with the correlations within the first of these levels that this investigation is concerned.

The specific problem is the correlation between different forms of sensory discrimination at different stages of practice The results of the few studies that have been made, have, in general, shown that sensory discrimination is rather highly specialized. That is, high ability in discriminating color or brightness may go with low ability in discrimmating tones or pressures or lifted weights or lengths of lines. The evidence has, however, been based either on too small a number of cases to be entirely convincing, or, on a comparison of discriminativeness with varying amounts of practice and interest.

Several questions or problems bearing on the matter have not been satisfactorily worked out .

1. The number of tests necessary to secure an adequate measure of an individual's capacity in discriminations It is certain that a single test or a few tests will not give a measure of sensory discrimination, whatever else it may give From a methodological point of view, it is important to discover how great the number of measurements must be in cases where practice is so notoriously effective as in sensory discrimination in order to furnish at least a fairly accurate measure.

2. The correlation between an individual's station in a group

1 The numbers in parenthesis refer to the title by the same number in the appended biblography 
in successive stages of practice and with different forms of discrimination At what point, if ever, in practice does an individual's station become constant, and how does this point vary with different forms of discrimination? This is the problem of the effects of equal practice on individual differences, on which evidence is very meagre.

3 . The nature of the change that takes place when discrimination is improved by practice and the factors that account for the improvement.

4 The common factors that may be involved in different forms of discrimination which might bring about an increase in correlation

The subject of sensory correlation has only in recent years received the attention it merits. Although many psychologists have recognized the importance of the problem and have made it the object of experimental inquiry, very few have been at all satisfied with their results In fact, there has scarcely been a statement made concerning sensory correlation that has not been seriously questioned by other investigators in the field The extremists, on the one side, maintain that the correlation between different sensory abilities is high and that the correlation between sensory discrimination and general intelligence is very high, or, perfect; while others maintain that there is little or no correlation Between these two extremes we find all degrees of variation.

\section{Description of Experimental Work}

A. Tests-General Description. The experimental work of this investigation is concerned with four forms of sensory discrimination,--the Discrimination of Pressure, of Length of Lines, Auditory Discrumination, and Brightness Discrimination. Each test was carried on for ten consecutive days and as nearly as possible at the same period of the day. There were fifty judgments to be given in each day's test, or five hundred judgments for each type of discrimination, so that in the four tests two thousand judgments were given by each subject. The eight subjects made, in all, sixteen thousand judgments. The method of right and wrong cases was used throughout and the order of stimulation in each test was determined by chance. These four tests were used partly because of the fact that previously published results have dealt with these forms of discrimination and partly because of the readiness with which they lend themselves to the measurement by the method of right and wrong cases. 
$B$. Order of Tests. The four tests were given in the following order to all subjects:

1 Discrimination of Pressure

2. Discrimination of Length of Lines.

3 Auditory Discrimination

4. Brightness Discrimination

This order was adhered to strictly for the reason that the various tests given to the different subjects would be made under the same conditions as far as the effects of practice were concerned It was not in the province of this study to deal with the transfer of practice

$C$ Subjects of the Experiment. Eight individuals were chosen, varying in age from seventeen to forty years of age, with different degrees of training, experience and interests. All subjects, however, had as a minımum the high school grade -work Two subjects were in the graduate department of Educational Psychology; one an instructor in Psychology, one a senior in the Literature and Science Course; one Junior; two Sophomores; and one Freshman in the College of Agriculture One of the Sophomores and the one Freshman were mature men, the Sophomore being a man of twenty-nine years of age, a graduate of a Normal School and having been a superintendent of schools for four years The Freshman was a man of twenty-four years of age and had taught in a city school system for three years. The Junior and the other Sophomore were average University students in the College of Agriculture.

The first four subjects named were men of w1de experience both in teaching or educational training and in the laboratory work of Educational Psychology.

The interest of all the subjects was exceedingly good, and every effort was made to make the tests accurate There was a decided effort, at all times, to make as high a record as possible. The writer, in most instances, gave a brief description of the purpose of the experiments in order that there would be an interest aroused by the subjects in their results. This type of motivation functioned exceedingly well and helped to stimulate each subject to his maximum effort in each test.

D. Description of the Apparatus and Methods Used. A brief description of each test will be outlined below:

\section{a Discrimination of Pressure}

In this test Whipple's Pressure-Pain Balance was used with a weight of 200 grams at the outer end of the lever and an 
increment weight of 20 grams Each subject took a comfortable position-the instrument being so placed that the subject's wrist came just over the edge of the table. The hand could then lie upon the hand rest, with the end of the forefinger projecting straight forward between the two tips of the balance The upper tip was so arranged as to come in permanent contact with the center of the finger nail The subject closed his eyes; at the word "Now," the first stimulus was given and two seconds later the second one was given. The subject was required to state, in terms of the latter, whether it was heavier or lighter. Every effort was exerted by the experimenter to make the two stimulations of the same duration and the same degree of application Occasionally the writer would stop and allow the subject to remove his finger for a short period, perhaps fifteen or twenty seconds, as many subjects felt a sort of numbness after a number of stimulations had been given.

\section{b. Discrimination of the Length of Lines}

For the discrimmation of length of lines eight cards, on which were engraved lines 20 and $20.3 \mathrm{~mm}$., were exposed, by means of the Jastrow memory apparatus The cards were so arranged in series that the chance order of presentation was maintained

The subject was seated before the apparatus in such a manner that his eyes were on a level with the lines Then a pair of lines were exposed for two seconds, the record of the time being kept with a metronome, beating seconds. The subject was required to judge whether the right line was longer than the left throughout one whole test. Then, in the following day's test, the subject was required to judge the left in terms of the right, and so alternating throughout the ten tests

\section{c. Auditory Discrimination.}

Seashore's audiometer was used for the tests in Auditory Discrimination (11). A room was chosen which would be as free from noise as possible The subjects were instructed to make use of their keener ear. All of the subjects, however, were normal in the point of hearing. One stimulus was placed at 28 and the other at 29 on the scale of the audiometer The stımuli were given in chance order, care being taken to make the tests of the same duration. The subject assumed a comfortable position, closed his eyes and kept them closed through- 
out the experiment. The judgments were given first in terms of the first stimulus, then, in terms of the second

\section{d. Brightness Discrimination}

Whipple's apparatus for brightness discrimination was used for the tests in brightness discrimination (11) The apparatus is a box fitted with a high-power frosted Tungsten lamp, the light of which is reflected from two independently adjustable white screens upon two oblong translucent windows, so placed in the face of the box as to give out as nearly as possible the same amount of light when the levers are set even on the scale

The apparatus was set up in a dark room and in such a position that the subjects' eyes came even with the apertures The levers regulating the reflectors were placed even at first in order to regulate the position of the apparatus so that the lights of the two would appear equal in intensity to the subjects. One lever was then set at $120^{\circ}$ and the other at $115^{\circ}$ The order of brightness in the two windows was one of chance. The subject was required to judge whether the right was darker or lighter than the left in one test, and the left in terms of the right in the next, and so on, alternating each test. Between tests the subject closed his eyes and kept them closed until the writer gave the signal, "ready"

III. Results and Discussion of the Experments with the Several Groups of Tests

The gross results of the various tests are indicated in Table I. This gives the per cent of right cases in the four tests for the eight subjects, together with the averages and mean variations.

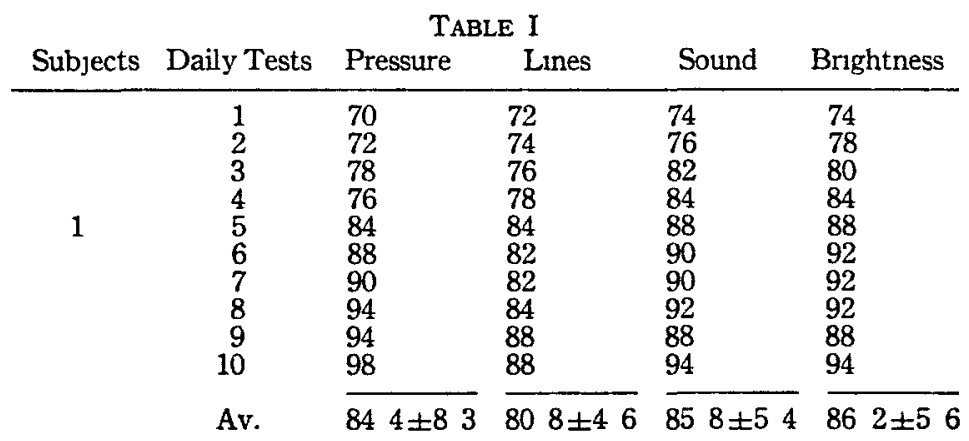


32

STEVENSON

TABLE I-Continued

Subjects Darly Tests Pressure Lines Sound Brightness

2

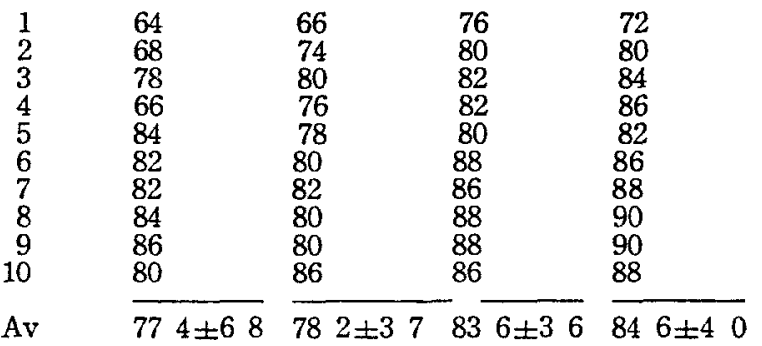

3

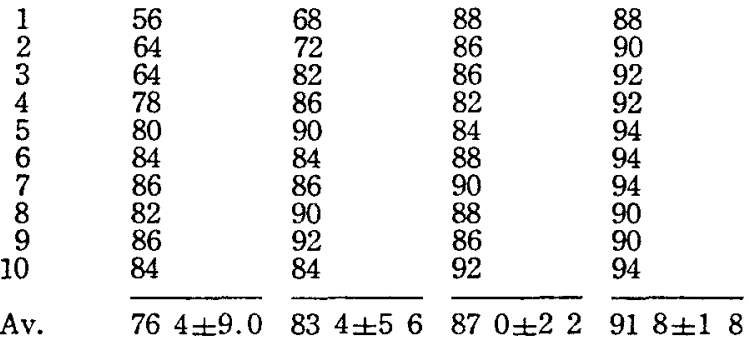

4

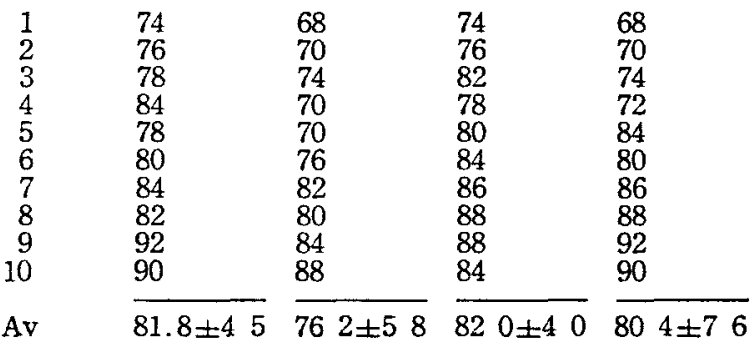

5

\begin{tabular}{|c|c|c|c|}
\hline $\begin{array}{l}70 \\
62 \\
72 \\
84 \\
82 \\
86 \\
82 \\
88 \\
90 \\
96\end{array}$ & $\begin{array}{l}68 \\
66 \\
74 \\
82 \\
84 \\
88 \\
80 \\
86 \\
86 \\
90\end{array}$ & $\begin{array}{l}70 \\
68 \\
74 \\
80 \\
86 \\
84 \\
88 \\
94 \\
90 \\
96\end{array}$ & $\begin{array}{l}72 \\
78 \\
74 \\
84 \\
86 \\
84 \\
90 \\
96 \\
94 \\
96\end{array}$ \\
\hline $31.2 \pm 7.9$ & $80.4 \pm 6.7$ & $83.0 \pm 8.0$ & $85.4 \pm 7.0$ \\
\hline
\end{tabular}


TABLE I-Continued

\begin{tabular}{|c|c|c|c|c|c|}
\hline Subjects & Daily Tests & Pressure & Lines & Sound & Brightness \\
\hline \multirow[t]{2}{*}{6} & $\begin{array}{r}1 \\
2 \\
3 \\
4 \\
5 \\
6 \\
7 \\
8 \\
9 \\
10\end{array}$ & $\begin{array}{l}70 \\
72 \\
76 \\
80 \\
90 \\
90 \\
84 \\
88 \\
86 \\
88\end{array}$ & $\begin{array}{l}70 \\
76 \\
74 \\
84 \\
80 \\
86 \\
80 \\
82 \\
92 \\
94\end{array}$ & $\begin{array}{l}76 \\
82 \\
86 \\
82 \\
84 \\
88 \\
84 \\
88 \\
88 \\
92\end{array}$ & $\begin{array}{l}82 \\
88 \\
90 \\
92 \\
88 \\
92 \\
92 \\
94 \\
90 \\
94\end{array}$ \\
\hline & Av. & $82.4 \pm 6.3$ & $818 \pm 5.8$ & $85.0 \pm 3.4$ & $90.2 \pm 2.5$ \\
\hline \multirow[t]{2}{*}{7} & $\begin{array}{r}1 \\
2 \\
3 \\
4 \\
5 \\
6 \\
7 \\
8 \\
9 \\
10\end{array}$ & $\begin{array}{l}76 \\
80 \\
82 \\
78 \\
84 \\
90 \\
90 \\
90 \\
92 \\
92\end{array}$ & $\begin{array}{l}74 \\
72 \\
78 \\
76 \\
80 \\
80 \\
80 \\
82 \\
86 \\
88\end{array}$ & $\begin{array}{l}76 \\
82 \\
74 \\
74 \\
88 \\
90 \\
92 \\
90 \\
88 \\
92\end{array}$ & $\begin{array}{l}76 \\
88 \\
86 \\
90 \\
88 \\
92 \\
94 \\
90 \\
92 \\
92\end{array}$ \\
\hline & Av. & $85.4 \pm 54$ & $79.6 \pm 36$ & $846 \pm 6.4$ & $888 \pm 3.4$ \\
\hline \multirow[t]{2}{*}{8} & $\begin{array}{r}1 \\
2 \\
3 \\
4 \\
5 \\
6 \\
7 \\
8 \\
9 \\
10\end{array}$ & $\begin{array}{l}68 \\
76 \\
88 \\
86 \\
84 \\
86 \\
86 \\
92 \\
92 \\
98\end{array}$ & $\begin{array}{l}70 \\
80 \\
82 \\
90 \\
86 \\
92 \\
92 \\
84 \\
90 \\
98\end{array}$ & $\begin{array}{l}78 \\
80 \\
82 \\
84 \\
88 \\
90 \\
88 \\
94 \\
92 \\
96\end{array}$ & $\begin{array}{l}84 \\
90 \\
94 \\
96 \\
96 \\
94 \\
96 \\
98 \\
96 \\
98\end{array}$ \\
\hline & $\mathrm{Av}$ & $856 \pm 57$ & $86 \quad 4 \pm 6 \quad 0$ & $872 \pm 49$ & $942 \pm 29$ \\
\hline
\end{tabular}

The following coefficients of correlation are calculated by the rank method developed by Spearman and also by the product-moment method of the Pearson-Bravais Formula.

TABLE II

Coefficients of Correlation of the Different Sensory Tests

Lines and Sound Discrimination

Spearman Pearson

Brightness and Sound

Pressure and Lines

$\begin{array}{rr}+90 & .92 \\ +.90 & 96\end{array}$

Pressure and Sound

Lines and Brightness

Pressure and Brightness

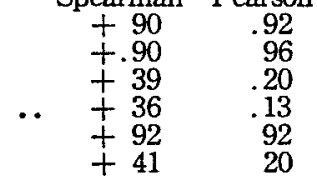


The most striking result revealed by the experiments consists in the very high correlations shown between the ranks based on the averages in all of the tests and particularly between sound, brightness and line discrimination. The correlations are very much higher than those reported by previous authors. A comparison with Burt's results shows this very clearly. He found correlations for discrimination as follows.

Touch and Weight
Touch and Pitch
Touch and Length
Weight and Pitch
Weight and Length
Pitch and Length

Average
+.49
+.12
+23
+29
+00
+09

Thorndike similarly finds a loose correlation between different forms of discrimination. Moreover, not only are the correlations for different sensitivities low or absent entirely, but even the correlation between drawing a line to equal a $100 \mathrm{~mm}$. line and one equal to a $50 \mathrm{~mm}$. line is only +.77 . The results in other words point not only to a high degree of independence of different forms of discrimination but also of any single form with varying data or content. My own results, however, show very close interrelations between the different sensory abilities when a sufficiently large number of experiments is made to furnish an adequate measure of an individual's capacity. Most of the investigations previously made, from which the conclusion has been drawn that the "sensitivities interrelate very loosely," have been based on one or a few experiments with large groups. The reliability of the coefficients is, therefore, low. Certainly when the ranks in any tests are based on ten series of experiments, each involving fifty judgments, there is no question that the coefficients are very high and the reliability great. The only departure is in the correlations with pressure discrimination. The experiments on pressure, however, are the least reliable because of certain sources of inaccuracy in the administration of the tests by the experimenter. With the particular type of instrument employed it is difficult to maintain constancy in the duration of the stimulus and to maintain a uniform rate of application of the stimulus, and, consequently, to avoid variations in amount of pressure. Moreover, the constant error arising when the lighter stimulus comes after the heavier affected the results with some subjects, notably subject 4 who gave but 2 erroneous judgments out of 250 , 
when the heavier stimulus followed the lighter. A further factor in reducing the coefficients is the fact that one subject ranked 8 in pressure discrimmation and 2 in all the other tests. With the rank method of correlation the differences of rank, 6 in each pair of correlations, reduced each of the coefficients 42. With a larger number of cases this factor in reduction would be less effective. The correlations with the 7 subjects for pressure with length of lines is .61 , with sound .75 , with brightness .74 .

The coefficients by the Pearson method were calculated for purposes of comparison with those of the rank method. The differences resulting are, in some cases, very marked. An inspection of the actual results in the tests suggests that neither method gives an adequate expression of the amount of correlation. The Pearson method tends to give undue weight to the extreme deviations from the average, while, on the other hand, the rank method gives undue weight to small differences.

The highest correlation is between discriminations of length and of brightness. This might, perhaps, be attributable to the fact that the same sense organ is involved The correlations indicate that the subjects who had difficulty in discriminating brightness also had difficulty in discriminating length Moreover, the correlations between brightness and length discriminations with the other forms are very similar.
Length with Sound Discrimination
Brightness with Sound Discrimmation
Length with Pressure Discrimination
Brightness with Pressure Discrummation
+90
+90
+39
+.41

However, the correlations between sound discrimination and discrimination of length or brightness are almost as close as the correlation between brightness and length Some other underlying factor must have been involved. The explanation of the high correlations obtained between the different forms of sensory discrimination studied seems to demand a modification of the extreme view of specialization and independent variability of mental functions of which Thorndike has been the chief defender. Some intermediate position between that taken by Thorndike and the one maintained by Spearman is suggested. In the face of these results, one could scarcely hold that the different forms of discrimination interrelate loosely. Interrelation is close but by no means perfect. Moreover, two of the factors which might cause high correlations have been eliminated as far as possible; namely, variation in the conscientiousness and good will of 
the subject, and variation in the amounts of practice. If, in a group of subjects, some were conscientious observers and others not, the ranks might give an appearance of correlation, but this correlation is in conscientiousness and not in discrimination. Again, if in a group the subjects tested started at different stages of practice and training, the result might, on a basis of ranks, either give a high correlation or a low correlation, but the coefficient would not then measure sensory discrimination, but something else. With these factors eliminated, we are reduced to some other common factor or factors which might be operative. Spearman's hypothetical "Central Factor" is suggested, but it is obscure and mysterious. To appeal to it is but to cloak our ignorance An extension of this investigation with a further analysis of the factors involved is contemplated. Until such results are at hand, a definite attempt at explanation will not be ventured by the writer.

One of the purposes of this investigation was to study the correlations shown at different stages of practice From the point of view of method in mental tests it is important to determine the number of tests necessary to give a reasonably accurate coefficient of correlation Moreover, such a study would throw light on the course of practice itself Theoretically, one might expect, since the real effect of practice is to reduce variability, that the coefficient of correlation in successive stages of practice would become high. This would be true however only on the supposition that practice took much the same course in different individuals, and that the effects of practice on different individuals, and with different forms of discrimination were equal. The results of correlation based on the averages of the first two, the fifth and sixth, and the last two tests, appear in Table III. The results of Table III are graphically represented in Plate I.

TABLE III

Correlation Based on First Two, Fifth and Sixth, Eighth and Tenth, and Last Two Tests

Senes

1 and 2,5 and 6,9 and 10,8 and 10

Lines and Sound

Lines and Pressure

Lines and Brightness

Sound and Pressure

Sound and Brightness

Bnghtness and Pressure

Average $\ldots$.

\begin{tabular}{rrrr}
.56 & 55 & 77 & 96 \\
11 & 16 & 48 & 58 \\
64 & 84 & 78 & .93 \\
00 & .70 & 77 & .82 \\
.93 & 83 & .77 & .90 \\
-18 & .41 & .44 & .68 \\
\hline 40 & .58 & .67 & .81
\end{tabular}




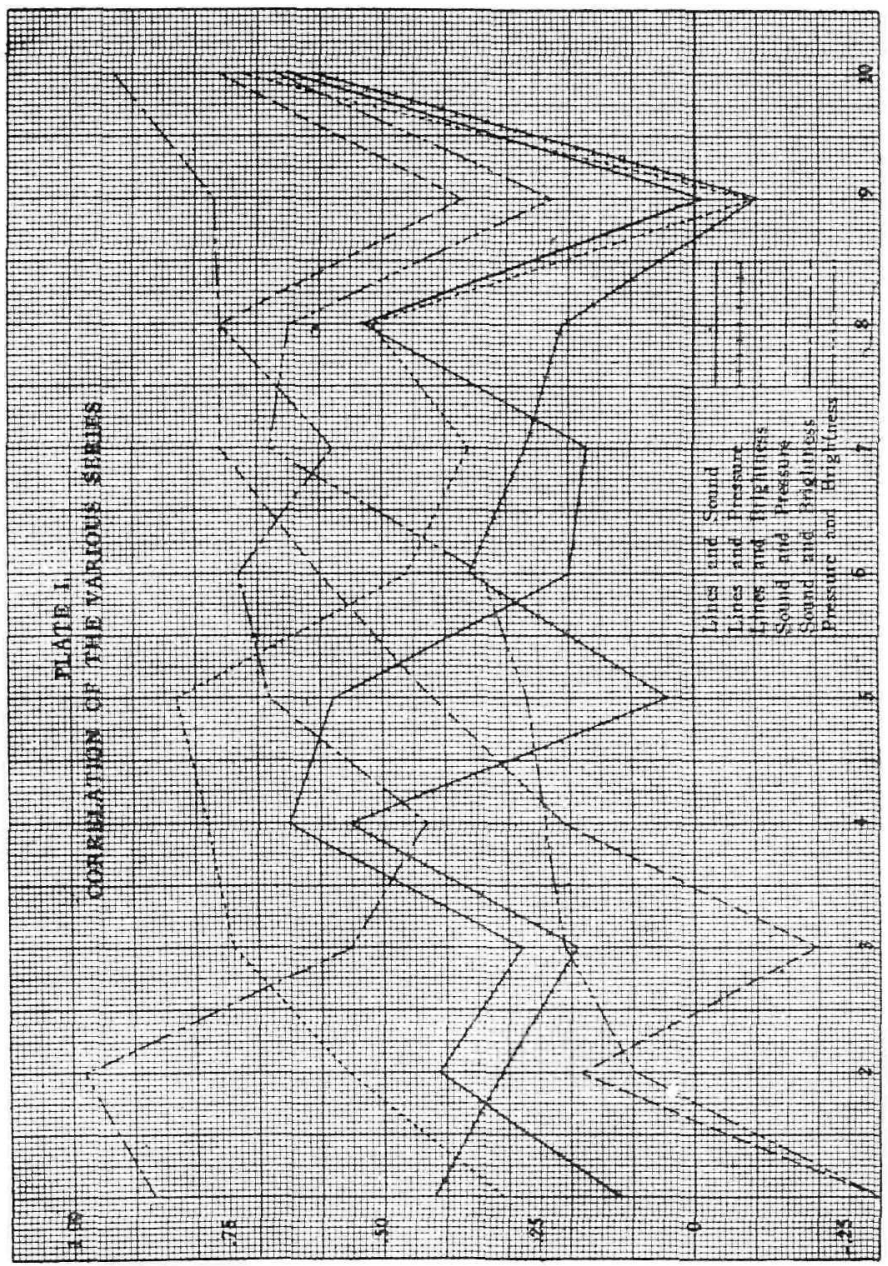

There is a general increase in the coefficients but the increase is not very marked, partly due to an unaccountable fluctuation in the ninth step of experiments. The correlations with each of the ten series of tests appear in Table IV.

The effects of practice in the different tests are indicated in the plates. In every case, there is a marked improvement. The course of practice is similar with the different individuals and with the different forms of discrimination. Practice 


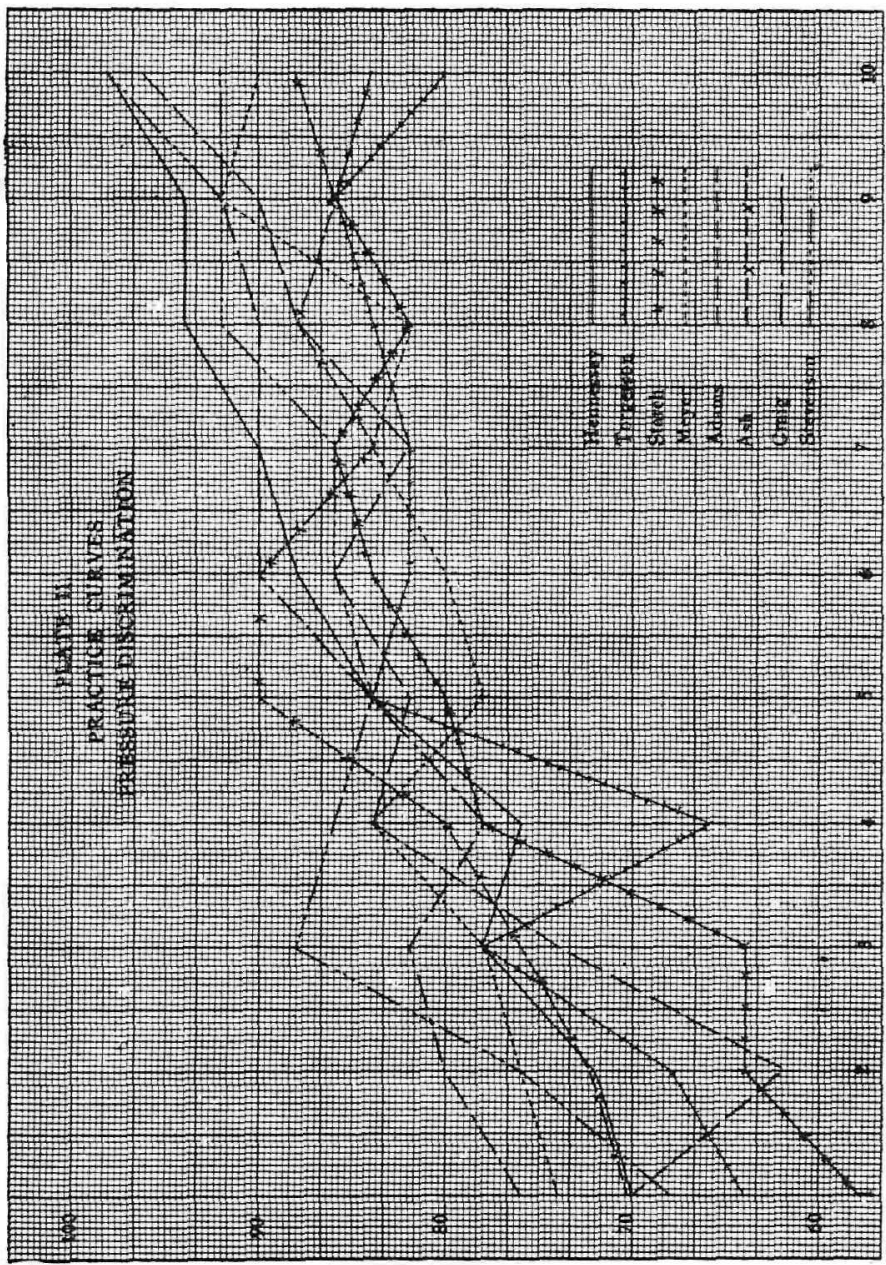

TABLE IV

Table of the Coefficients of Cortelation of the Ten Sertes of Sensory Tests

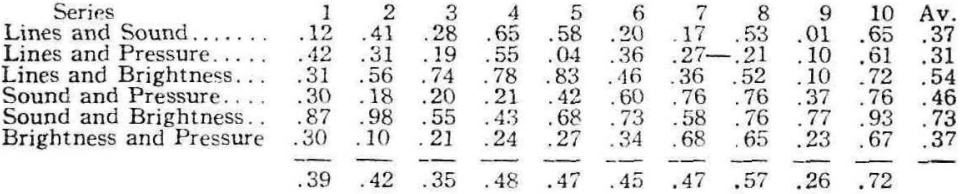


effect is most marked in the discrimination of pressure, and the increase is gradual.

\section{Conclusions}

The results of this investigation seem to justify the following conclusions .

1. The correlations between different forms of sensory discrimination are, in every case, positive and usually very high. The range is from .39 to .93 When correction is made for accidental variations, the range is from .71 to .93 . These coefficients justify a modification of present-day opinion with regard to the independence of different sensory abilities.

2. The effect of practice is to increase the coefficients. This was shown by calculating the coefficients from the first two, fifth and sixth, and last two tests, and by calculating the coefficients for each of the ten series of experiments.

The coefficients fluctuate considerably, and there appears to be no point in the course of practice where an individual's station in the group becomes relatively constant

3. The correlations are highest between brightness and length discrimination, but they are practically as high between sound discrimination and brightness or length.

4. Pressure discrimination correlates least with the other tests. Certain unavoidable sources of inaccuracy in making experiments account in considerable part for this fact

5. The effect of practice is similar in the different tests and with different individuals.

\section{Bibliography}

I BRown, William Some Experimental Results in the Correlation of Mental Abilities British Journal of Dsychology, Vol 3, p. 296

2. BURT, CYrur Expermental Tests of General Intelligence Britush Journal of Psychology, Vol 3, p 94

3. BurRIS, $W$ P. The Correlations of the Atilities Involved in Secondary School Work Columbra, University Contributions to Education, Philosophy and Psychology, Vol. II, No 2, p 16

4. GaLtoN, FrancIS Inquiries into Human Faculty.

5 JAmes, William The Principles of Psychology Vol I, Chap. I3-Discrimination and Comparison

6. Pearson, KarL. Grammar of Science and Edition, Chapter on Correlation

7. SEASHORE, C E Hearing Abslity and Discriminative Sensibility for Pitch The Untversity of Iowa Studies in Psychology, Vol II, pp $55-64$

8 SPEARMAN, C S General Intelligence Objectively Determined and Measured American Journal of Psychology, Vol. 15, pp. 201-292 
9. Thorndike, EDWard L. Educational Psychology. Ist Edition, Chap. IV-The Relationships beween Mental Traits. and Edition, p. I9I.

10. The Relation of Accuracy in General in Sensory Discrimination to General Intelligence. American Journal of Psychology. Vol. 20, p. 364.

1. Whipple, GuY M. Manual of Mental and Physical Tests.

I2. Wissler, Clark. The Correlation of Mental and Physical Tests. Psychological Rerica Monograph Supplement, June Igor.

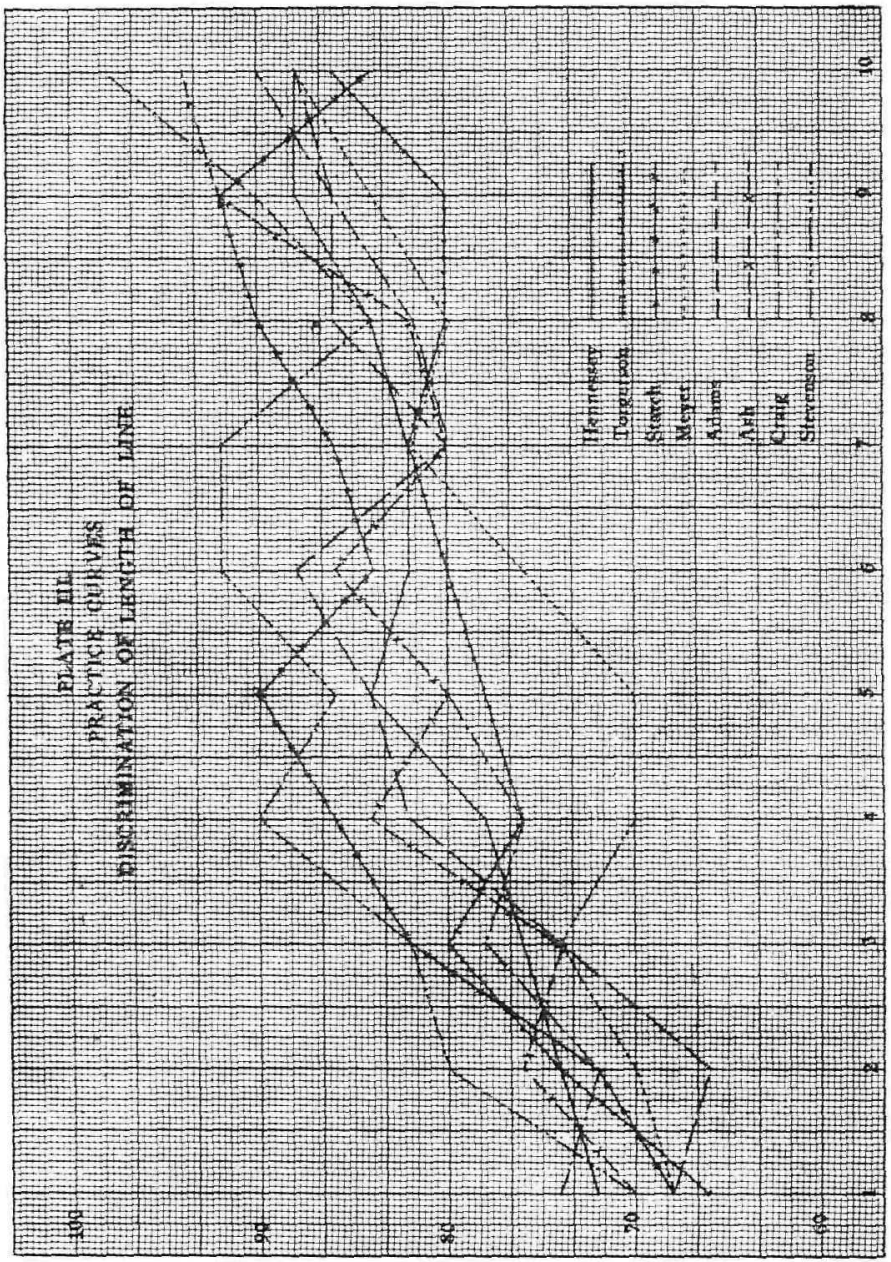




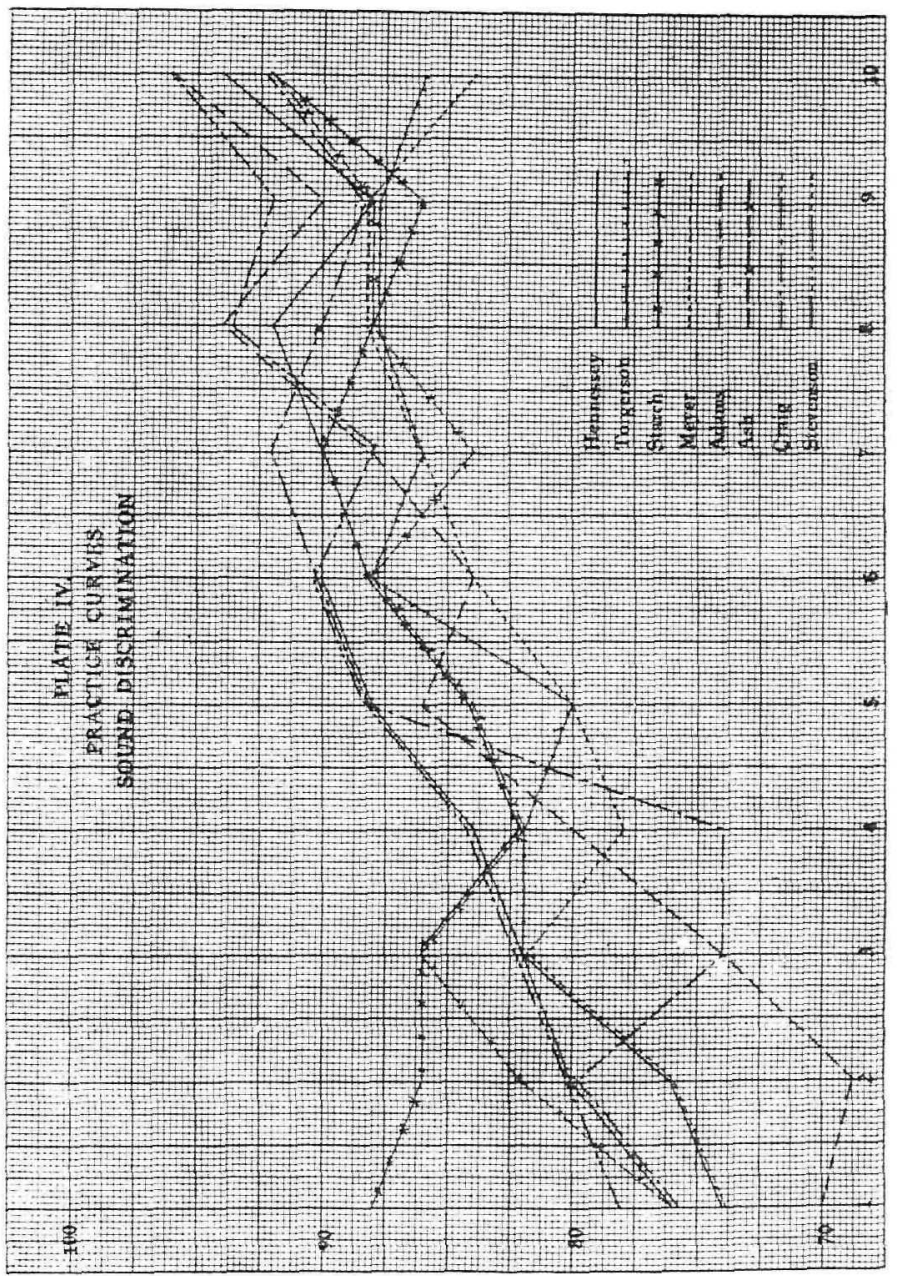




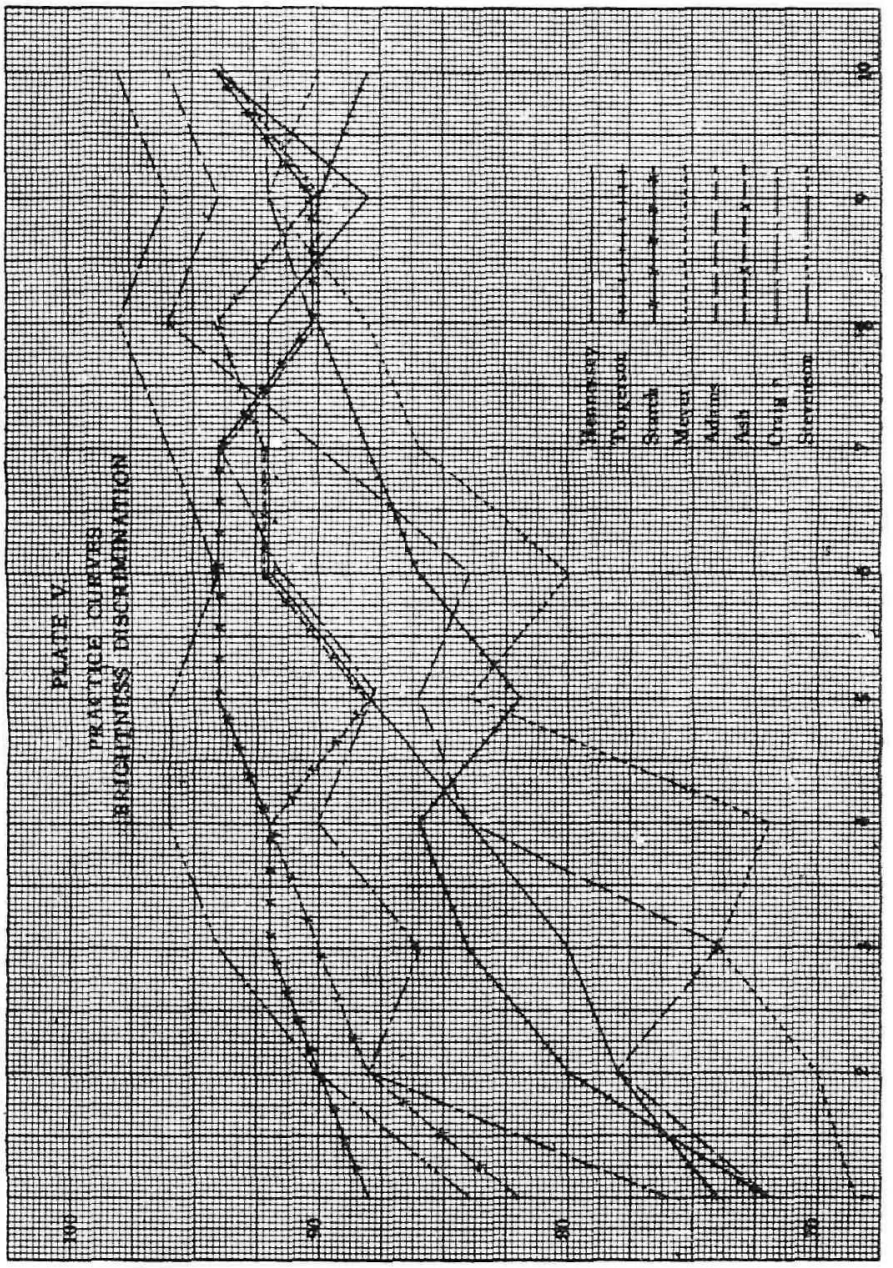

